\title{
Mandibular Birinci ve İkinci Premolar Dişlerin Kök ve Kanal Morfolojilerinin Panoramik Radyogram ile Değerlendirilmesi: Epidemiyolojik Çalışma
}

\author{
Sevcihan Günen Yılmaz(0000-0002-4435-288X) ${ }^{\alpha}$, Hümeyra Tercanlı Alkış(0000-0001-9660-4228) ${ }^{\alpha}$, \\ Ayşe Taş(0000-0003-1576-9560) ${ }^{\alpha}$
}

Selcuk Dent J, 2021; 8: 708-712 (Doi: 10.15311/selcukdentj.778584)

Basvuru Tarihi: 11 Ağustos 2020 Yayına Kabul Tarihi: 21 Aralık 2020

öz

Mandibular Birinci ve İkinci Premolar Dişlerin Kök ve Kanal Morfolojilerinin Panoramik Radyogram ile Değerlendirilmesi: Epidemiyolojik Çalışma

Amaç: Dişlerdeki kök ve kanal morfolojisinin varyasyonları endodontik tedavinin planlaması ve prognozu üzerinde büyük etkiye sahiptir. Tüm dişlerin normal anatomik yapıda olduğu varsayılarak, kök ve kanal sayısı değerlendirilmeden yapılacak cerrahi işlemler olumsuz sonuçlar doğurabilir. Tedavi öncesi ve sırasında görüntüleme yöntemleri gelişebilecek komplikasyonları önleyebilir. Bu çalışmanın amacı, geniş bir yaş aralığında mandibular birinci ve ikinci premolar dişlerin kök ve kanal sayılarının dijital panoramik radyografik görüntüler ile değerlendirilmesidir.

Gereç ve Yöntemler: Rastgele seçilen bireylerden elde edilen 1030 dijital panoramik radyografik görüntü mandibular premolar dişlerin kök ve kanal morfolojilerini değerlendirmek amacıyla, retrospektif olarak iki oral ve maksillofasiyal radyoloji uzmanı tarafından incelendi. Dişlerin kök ve kanal morfolojileri Vertucci sınıflanmasına göre değerlendirildi. Cinsiyet ve yaş ile ilgili dağılımlarını karşılaştırmak için ki-kare testi kullanıldı. $\mathrm{P}<0.05$ anlamlı kabul edildi.

Bulgular: Çalışma grubunun yaş ortalaması $22.8 \pm 7.7$ yıl idi. Cinsiyetler arası yaş farkı istatistiksel olarak anlamlı değildi. Cinsiyetler arasında birden fazla kök ve kanal içeren diş sayısı açısından istatistiksel olarak anlamlı bir farkllık bulunmadı. Mandibular sol ikinci premolar dişin kök ve kanal sayısı ile mandibular sağ ikinci premolar dişin kanal sayısı erkek bireylerde kadınlara göre daha fazla tespit edildi.

Sonuç: Endodontik tedavi sırasında veya tedavideki başarısızlıkta dişlerin kök ve kanal yapılarında muhtemel anatomik varyasyonlar olabileceği akılda tutulmalıdır. Mandibular birinci ve ikinci premolar dișler büyük oranda tek kök kanal yapısına sahiptir.

\section{ANAHTAR KELIMELER}

Küçük azı, Mandibula, Panoramik radyografi

Kök kanal tedavisinin amacı pulpa dokusunun tam veya tama yakın çıkarılıp, kök kanalları genişletildikten sonra biyouyumlu materyaller kullanılarak, sızdırma olmadan kök ucuna kadar doldurulmasıdır., ${ }^{1,2}$ Kanalın tamamen temizlenmesi ve şekillendirilmesi kök kanal tedavisindeki en önemli noktadır ve klinik başarıy belirler. Klinisyenlerin dişlerin iç (kanal sayısı) ve dış (kök sayısı) morfolojileri hakkında bilgi sahibi olması, tanı, endodontik tedavinin planlanması ve prognoz açısından önemlidir. ${ }^{3}$ Tüm dişlerin normal anatomik yapıda olduğu varsayılarak, kök ve kanal sayısı değerlendirilmeden

\section{ABSTRACT}

Evaluation of Root and Canal Morphologies of the Mandibular First and Second Premolar Teeth with Panoramic Radiogram: Epidemiologic Study

Background: Variations of root and duct morphology in teeth; is influential on the planning and prognosis of endodontic treatment. Assuming that all teeth have a normal anatomical structure, surgical procedures without evaluating the number of roots and canals may result in negative results. Imaging methods before and during treatment can prevent complications that may develop. The aim of this study is to evaluate the root and canal numbers of mandibular first and second premolar teeth with digital panoramic radiographic images in a wide age range.

Methods: 1030 digital panoramic radiographic images obtained from randomly selected individuals were retrospectively examined by two oral and maxillofacial radiologists to evaluate the root and canal morphology of mandibular premolar teeth. Root and canal morphologies of teeth were evaluated according to Vertucci classification. The chi-square test was used to compare their gender and age-related distributions. $P<0.05$ was considered significant.

Results: The mean age of the study group was $22.8 \pm 7.7$ years. Age difference between genders was not statistically significant. There was no statistically significant difference in the number of teeth with multiple roots and canals between the genders. Mandibular left second premolar tooth root and canal number and mandibular right second premolar tooth canal number were found more in male subjects than in females.

Conclusion: It should be kept in mind that there may be possible anatomical variations in the root and canal structures of the teeth during endodontic treatment or failure in treatment. Mandibular first and second premolar teeth largely have a single root canal structure.

\section{KEYWORDS}

Mandible, Panoramic radiography, Premolar

yapılacak cerrahi işlemler olumsuz sonuçlar
doğurabilir. Tedavi öncesi ve tedavi sırasında kullanılan görüntüleme yöntemleri gelişebilecek olası komplikasyonları önleyebilir.

Kök kanal sistemi ana kök kanalı, dentin kanalları, aksesuar kanallar, kanal ramifikasyonları, apikal deltalar ve transvers anastomozlardan oluşan kompleks bir yapıdan oluşur. ${ }^{4}$ Kök ve kanal anatomisini değerlendiren çalışmalarda değerlendirilen dişler için, çok farklı kök ve kanal

\footnotetext{
${ }^{\alpha}$ Akdeniz Üniversitesi Diş Hekimliği Fakültesi Ağız Diş ve Çene Radyolojisi AD, Antalya, Türkiye
} 
sayıları ve şekilleri gösterilmiştir. Kök ve kanal morfolojileri için 1969 yılında Weine ve arkadaşları tarafından bir sınıflandırma yapılmıştır. ${ }^{5}$ Yakın zamanda Vertucci tarafından önerilen sınıflandırmada kök ve kanal yapısı sekiz alt tipe ayrılarak sınıflandırılmıştır. ${ }^{6}$ Vertucci sınıflandırması kullanılarak birçok çalışma yapılmıştır. Ancak bu yöntemde sınıflandırılmayan kök ve kanal morfolojisine sahip dişler radyografilerde görülebilir.

Dişlerde anatomik varyasyonlar sıklıkla daimi mandibular premolar dişlerde görülür. Mandibular premolar dişlerin kök ve kanal morfolojilerinin kadın ve erkekler arasında ve farklı etnik gruplarda değişiklik gösterebileceği belirtilmiştir. ${ }^{7-10}$ Mandibular premolar dişlerin kök ve kanal yapısı genetik ve ırksal farklılıklar gösterebilmektedir.7,11 Çin, Avustralya ve Sahra altı Afrikalı nüfusta, ek kanal ve kök yapısına sahip dişlerin daha fazla görüldüğü bildirilmiştir. ${ }^{12}$ Çeşitli çalışmalarda mandibular birinci ve ikinci premolarların kök ve kanal kök sayıları değerlendirilmiştir. Vertucci' nin çalışmasında mandibular birinci premolar dişlerde tek kanal bulunma oranı \% 74, iki kanal bulunma oranı \%25.5 ve üç kanal bulunma oranı \%0.5 olarak bulunmuştur. İkinci premolar dişlerde ise tek kanal \% 97.5, iki kanal \% 2.5 olarak saptanmış olup, mandibular ikinci premolar dişlerde üç kanal yapısı görülmemiştir. ${ }^{6}$ Sert ve arkadaşlarının çalışmasında mandibular birinci ve ikinci premolar dişler sırasıyla, \% 62 ve \% 71 oranında tek kanal yapısına sahiptir. ${ }^{7}$

Çekilmiş dişlerde kök sayısı sıklıkla şeffaflaştırma metodu olmak üzere; boya filtrasyon metodu ve kesit alma metodu kullanılarak hesaplanır. ${ }^{12}$ Çekim yapılmamış vital dişlerde ise bu değerlendirme radyolojik yöntemler kullanılarak yapılır. Konvansiyonel görüntülemeler sıklıkla kullanılsa da üç boyutlu olarak değerlendirme imkânı sağlaması ve süperpozisyonları ortadan kaldırması nedeni ile gerektiğinde konik ışınlı bilgisayarlı tomografiden de yararlanılmalıdır. ${ }^{13,14}$

Bu çalışmada Türkiye'nin güney bölgesinde (Antalya ve etrafı) yaşayan çocuk ve erişkin bireylerde, dijital panoramik radyografik görüntüler ile mandibular birinci ve ikinci premolar dişlerin kök ve kanal sayılarının belirlenmesi ve bunların cinsiyet ile ilişkisinin değerlendirilmesi amaçlanmıştır.

\section{GEREÇ VE YÖNTEMLER}

$\mathrm{Bu}$ çalışmanın yürütülmesi Akdeniz Üniversitesi Tıp Fakültesi Klinik Araştırmalar Etik Kurulu tarafından 08.01.2020 tarihinde KAEK-12 karar numarası ile onaylandı. Bu çalışma retrospektif, kesitsel, tek merkezli bir çalışma olarak tasarlandı. Çalışmada mandibular birinci ve ikinci premolar dişlerin kanal ve kök sayılarının değerlendirmesi amaçlandı. Çalışma için, Akdeniz Üniversitesi Ağız Diş ve Çene Radyolojisi Anabilim Dalı'na rutin dental muayene için müracaat eden, 11-62 yaş arası toplam 1030 bireye ait dijital panoramik radyografik görüntü rastgele seçildi. Dişlerin kök ve kanal sayılarının değerlendirilmesi Vertucci sınıflandırmasına göre yapıldı. ${ }^{7}$ Panoramik görüntü kalitesi iyi olan hastaların mandibular birinci ve ikinci premolar dişlerinin kök ve kanal sayıları değerlendirildi.

Dijital panoramik radyografik görüntü kalitesi olmayan, diş gelişimini etkileyen konjenital-edinsel hastalık öyküsü bulunan, mandibular premolar dişlerde eksiklik olan, birinci veya ikinci premolar diş olduğu konusunda şüphe duyulan dişler, kron bütünlüğü bozulmuş ve kök çürüğü bulunan dişler, kök rezorpsiyonu gözlenen dişler, kanal tedavisi görmüş olan bireyler çalışmaya dâhil edilmedi. Hastaların yaş, cinsiyet gibi demografik verilerine elektronik dosyalarından ulaşıldı. Yaş gruplarına göre hastaların dağılımı Tablo 1'de gösterilmektedir.

Tablo 1

\section{Hastaların yaş grubuna göre dağılımı}

\begin{tabular}{|lll|}
\hline Yaş grubu & Hasta sayısı & Yüzde \\
\hline $10-19.9$ & 402 & $\% 39.02$ \\
\hline $20-29.9$ & 413 & $\% 40.09$ \\
\hline $30-39.9$ & 189 & $\% 18.34$ \\
\hline $40-49.9$ & 24 & $\% 2.33$ \\
\hline $50-63$ & 2 & $\% 0.19$ \\
\hline
\end{tabular}

Kanal ve kök sayısı için retrospektif olarak değerlendirilen tüm görüntüler Planmeca ProMax (Planmeca Oy, 00880 Helsinki, Finlandiya) cihazı ile hasta ayakta vertikal pozisyonda ve uygun radyasyon dozu ile aynı radyoloji teknisyeni tarafından çekilmişti ve kök ve kanal sayısı açısından alanında en az yedi yıllık deneyime sahip iki oral ve maksillofasiyal radyoloji uzmanı tarafından değerlendi. Değerlendirme karanlık odada, loş ışık altında ve uygun bir büyüteç kullanılarak yapıldı. Rastgele seçilen 250 dijital panoramik radyografik görüntüde gözlemci içi ve gözlemciler arası uyum değerlendirildi.

İstatistiksel analiz

Tüm verilerin değerlendirilmesi SPSS istatistiksel analiz programı (Statistical Package for Social Sciences; 21,0, SPSS Company, Illinois, USA) kullanılarak yapıldı. Gözlemci içi ve gözlemciler arası uyum değerlendirilirken Kappa katsayısı kullanıldı. Cinsiyetler arası, mandibular birinci ve ikinci premolar dişlerin kök ve kanal sayısının karşılaştırılması x2 (ki-kare) testi kullanılarak yapıldı. P $<0.05$ istatistiksel olarak anlamlı kabul edildi.

\section{BULGULAR}

Bu çalışmaya toplam 1030 çocuk ve erişkin birey dâhil edildi. Hastaların 578' i kadın (\% 56.1), 452' i erkekti (\% 43.9). Tüm grubun yaş ortalaması $22,8 \pm 7.7$ (minimum yaş: 11, maksimum yaş: 62); kadınların yaş ortalaması $23.1 \pm 7.5$ yıl (minimum yaş: 11, maksimum yaş: 47 ), erkeklerin yaş ortalaması $22.5 \pm 7.9$ (minimum yaş: 11 , maksimum yaş: 62) yıldı. 
Cinsiyetler arası yaş farkı istatistiksel olarak anlamlı değildi $(p>0.05)$. Hastaların \% 1.2'sinde $(n=13)$ birden fazla kök ve \%10.2'sinde $(n=106)$ birden fazla kanal morfolojisine sahip mandibular premolar diş tespit edildi. Erkeklerde birden fazla sayıda kökü olan mandibular premolar diş sayısı 11 ve birden fazla kanalı olan mandibular premolar diş sayısı 51 iken kadınlarda bu sayılar 2'ye 44 olarak belirlendi. Cinsiyetler arasında birden fazla kök ve kanal içeren diş sayısı açısından istatistiksel olarak anlamlı bir farklılık bulunmadı $(p=$ 0.15). Mandibular birinci ve ikinci premolar dişlerin kök ve kanal sayılarının cinsiyetlere göre dağılımı Tablo 2'de gösterilmektedir. Tablo 3'te ise gözlemci içi ve gözlemciler arası uyum katsayıları verilmiştir.

Tablo 2.

Mandibular birinci ve ikinci premolar dişlerin kök ve kanal sayılarının dağılımı

\begin{tabular}{|c|c|c|c|c|c|c|c|c|c|c|c|c|c|c|}
\hline \multirow{3}{*}{ Parametre } & \multicolumn{3}{|c|}{ kadın } & \multicolumn{3}{|c|}{ erkek } & \multirow{3}{*}{$p$} & \multirow{2}{*}{\multicolumn{3}{|c|}{$\begin{array}{l}\text { KADIN } \\
\text { kanal }\end{array}$}} & \multirow{2}{*}{\multicolumn{3}{|c|}{$\begin{array}{c}\text { ERKEK } \\
\text { kanal }\end{array}$}} & \multirow{3}{*}{ p } \\
\hline & \multicolumn{3}{|c|}{ kök } & \multicolumn{3}{|c|}{ kök } & & & & & & & & \\
\hline & 1 & 2 & 3 & 1 & 2 & 3 & & 1 & 2 & 3 & 1 & 2 & 3 & \\
\hline $\begin{array}{l}\text { sol birinci } \\
\text { premolar } \\
\text { hasta } \\
\text { sayısı }\end{array}$ & 577 & 1 & - & 450 & 2 & - & 0.58 & 560 & 18 & - & 437 & 15 & - & 0.86 \\
\hline $\begin{array}{l}\text { sol ikinci } \\
\text { premolar } \\
\text { hasta } \\
\text { sayısı }\end{array}$ & 578 & - & - & 447 & 5 & - & 0.01 & 573 & 5 & - & 441 & 11 & - & 0.07 \\
\hline $\begin{array}{l}\text { sağ birinci } \\
\text { premolar } \\
\text { hasta } \\
\text { sayısı }\end{array}$ & 577 & 1 & - & 451 & 1 & - & 1.00 & 560 & 17 & 1 & 440 & 12 & - & 0.65 \\
\hline $\begin{array}{l}\text { sağ ikinci } \\
\text { premolar } \\
\text { hasta } \\
\text { sayısı }\end{array}$ & 578 & - & - & 449 & 3 & - & 0.08 & 574 & 4 & - & 439 & 13 & - & 0.01 \\
\hline
\end{tabular}

\section{Tablo 3.}

\section{Gözlemci içi ve gözlemciler arası kappa değerleri}

\begin{tabular}{|c|c|c|c|}
\hline & Parametre & Gözlemci 1 & Gözlemci 2 \\
\hline \multirow{8}{*}{ Gözlemci 1} & $\begin{array}{l}34 \text { numaralı diş kök } \\
\text { sayısı }\end{array}$ & 1 & 1 \\
\hline & $\begin{array}{l}34 \text { numaralı diş } \\
\text { kanal sayısı }\end{array}$ & 0.896 & 1 \\
\hline & $\begin{array}{l}35 \text { numaralı diş kök } \\
\text { sayısı }\end{array}$ & 0.855 & 1 \\
\hline & $\begin{array}{l}35 \text { numaralı diş } \\
\text { kanal sayısı }\end{array}$ & 0.871 & 0.931 \\
\hline & $\begin{array}{l}44 \text { numaralı diş kök } \\
\text { sayısı }\end{array}$ & 1 & 1 \\
\hline & $\begin{array}{l}44 \text { numaralı diş } \\
\text { kanal sayısı }\end{array}$ & 0.896 & 1 \\
\hline & $\begin{array}{l}45 \text { numaralı diş kök } \\
\text { sayısı }\end{array}$ & 1 & 1 \\
\hline & $\begin{array}{l}45 \text { numaralı diş } \\
\text { kanal sayısı }\end{array}$ & 0.853 & 0.921 \\
\hline \multirow{8}{*}{ Gözlemci 2} & $\begin{array}{l}34 \text { numaralı diş kök } \\
\text { sayısı }\end{array}$ & 1 & 1 \\
\hline & $\begin{array}{l}34 \text { numaralı diş } \\
\text { kanal sayısı }\end{array}$ & 1 & 0.896 \\
\hline & $\begin{array}{l}35 \text { numaralı diş kök } \\
\text { sayısı }\end{array}$ & 1 & 1 \\
\hline & $\begin{array}{l}35 \text { numaralı diş } \\
\text { kanal sayısı }\end{array}$ & 0.931 & 0.931 \\
\hline & $\begin{array}{l}44 \text { numaralı diş kök } \\
\text { sayısı }\end{array}$ & 1 & 1 \\
\hline & $\begin{array}{l}44 \text { numaralı diş } \\
\text { kanal sayısı }\end{array}$ & 1 & 0.896 \\
\hline & $\begin{array}{l}45 \text { numaralı diş kök } \\
\text { sayısı }\end{array}$ & 1 & 1 \\
\hline & $\begin{array}{l}45 \text { numaralı diş } \\
\text { kanal sayısı }\end{array}$ & 0.921 & 0.853 \\
\hline
\end{tabular}

Mandibular sağ ve sol birinci premolar dişlerin kanal ve kök sayıları değerlendirildiğinde; 1030 adet sol mandibular birinci premolar dişin 1027 (\% 99.7) tanesi tek köklü, 3 (\% 0.3) tanesinin ise iki köklü olduğu tespit edildi. Üç köklü sol mandibular birinci premolar diş tespit edilmedi. Aynı dişin 997 (\% 96.8) tanesi tek kanallı ve 33 (\% 3,2) tanesi iki kanal yapısına sahipti. Üç kanallı sol birinci premolar diş tespit edilmedi. Mandibular sağ birinci premolar dişlerin ise 1028 (\% 99.8) tanesi tek köklü, 2 (\% 0.2) tanesi iki köklü tespit edildi. Üç köklü sağ mandibular birinci premolar diş tespit edilmedi. Aynı dişlerin 1000 (\% 97.1) tanesi tek kanallı, 29 (\% 2.8) tanesi iki kanallı ve 1 (\% 0.1) tanesinin 3 kanallı olduğu tespit edildi. Toplam 2060 birinci premolar dişin 2055 (\% 99.7) tanesi tek köklü, 5 tanesi (\% 0.3)'ü iki köklü olarak tespit edildi. Toplam 2060 birinci premolar dişin 1997 (\%96.9) tanesi tek kanallı, 62 (\% 3) tanesi iki kanallı ve bir (\% 0.1) tanesi üç kanallı olarak tespit edildi.

Mandibular ikinci premolar dişlerin kanal ve kök sayısı değerlendirildiğinde; 1030 tane sol mandibular ikinci premolar dişin 1025 (\% 99.5) tanesi tek köklü, 5 (\% 0.5) tanesi iki köklü tespit edildi. Üç köklü sol mandibular ikinci premolar diş tespit edilmedi. Aynı dişin 1014 (\% 98.4) tanesi tek kanallı, 16 (\% 1.6) tanesi iki kanallı olarak tespit edildi. 1030 tane sağ mandibular ikinci premolar dişin 1027 (\% 99.7) tanesi tek köklü, 3 (\% 0.3) tanesi iki köklü tespit edildi. Aynı dişin 1013 (\% 98.3) tanesi tek kanallı, 17 (\% 1.7) tanesi iki kanallı olarak tespit edildi. 2060 adet mandibular ikinci premolar dişin 2052 (\% 99.6) tanesi tek köklü, 8 (\% 0.4) tanesi iki köklü olarak tespit edildi. Mandibular ikinci premolar dişlerin 2027 (\% 98.3) tanesi tek kanallı, 33 (\% 1.7) tanesi ise iki kanallı olarak tespit edildi.

İki kök yapısına sahip beş mandibular premolar dişin üç tanesi erkek, iki tanesi kadın bireylerde görülürken, iki kök yapısına sahip sekiz adet mandibular ikinci premolar dişin hepsi erkek bireylerde görüldü. Cinsiyetler arasında kanal sayısı birden fazla olan mandibular birinci ve ikinci premolar diş sayısı açısından anlamlı farklılık yoktu ( $p>0.05)$.

Vertucci sınıflandırmasına göre mandibular birinci premolar dişlerde tip I (\% 91.2), tip V (\% 3.7), tip III (\% 2.6), tip IV (\% 1,4), ve diğer tipler \% 1.1 (tip II ve tip VI) oranında görülmektedir. Mandibular ikinci premolar dişlerde ise tip I (\% 89.2), tip V (\% 4.7), tip III (\% 2.6), tip IV (\% 1.4), ve diğer tipler \% 2.1 (tip II, tip VII ve tip VIII) oranında görülmektedir.

Tek köklü birinci ve ikinci premolar dişlerin oranı benzerdi (sırasıyla; \% 99.7, \% 99.6). Tek kanallı birinci premolar diş sayısı (\% 96.9), tek kanallı ikinci premolar diş sayısına (\% 98.3) göre daha azdı. Üç kanallı diş 
yüzdesi mandibular birinci premolar dișlerde \% 0.3 iken, ikinci premolar dişlerde üç köklü diş tespit edilmedi.

\section{TARTIŞMA}

Tek köklü dişler genellikle tek kanal yapısına sahiptir. Ancak iki kanal yapısı da nadir değildir. Dişlerin kök ve kanal morfolojisi ve sayısı ırklar arasında farklılıklar gösterebilir. Ayrıca ileri yaşlarda kök ve kanal morfolojisinde de birtakım değişiklikler meydana gelmektedir.

Endodontik tedavilerde başarısızlık ve komplikasyonların en önemli nedenlerinden biri, tedavi uygulanan dişlerin kök ve kanal anatomisindeki varyasyonlar nedeniyle değerlendirilemeyen ve doldurulamayan kanallardır. Bu durum mandibular birinci premolar dişlerde çok sık görülür. ${ }^{1}$ Tespit edilemeyen kök ve kanallarda kalan mikroorganizmalar çoğalarak endodontik tedavinin başarısız olmasına neden olurlar. Kök kanal tedavisinde başarısızlık nedenlerinin değerlendirildiği Hoen ve Pink'in çalışmasında hastalarda \% 42 oranında tedavi edilmemiş kanal varlığı gösterilmiştir. ${ }^{15}$

Daimi alt premolar dişlerde anatomik varyasyonlara rastlanmaktadır. Cleghorn ve ark.'nın mandibular birinci premolar dişlerin kanal ve kök sayısını değerlendiren ve 6700 dişin değerlendirildiği çalışmalarında bu dişlerin \% 98'i tek köklü, \% 1.8'i iki köklü ve \% 0.2'si üç köklü olarak bulunmuştur. Dört köklü diş sayısı ise \% 0.1'den daha az olarak tespit edillmiştir. ${ }^{11}$ Aynı çalışmada bu dişlerin \% 75.8'i tek kanal, \% 24.2'si ise birden fazla kanala sahipti. ${ }^{11}$ Yine aynı araştırmacı grubun 7700 mandibular ikinci premolar dişin kök ve kanal sayısını değerlendirdikleri çalışmalarında, dişlerin neredeyse tamamının tek köklü (\% 99.6) olduğu, iki köklü (\% 0.3) ve üç köklü (\% $0.1)$ dişlerin ise oldukça nadir görüldüğü belirtilmiştir. ${ }^{9}$ $\mathrm{Bu}$ çalışmada dişlerin \% 91'i tek kanallı olarak bulunmuş olup, mandibular ikinci premolar dişlerde birden fazla kanal ve kök sayısı olan diş oranı mandibular birinci premolar dişlere oranla daha fazla bulunmuştur. 9,11

Genel olarak mandibular ikinci premolar dişlerin birden fazla kanal yapısına sahip olmasına nadiren rastlanılmaktadır ve üç-dört kanallı olan bu premolar dişler vaka sunumları şeklinde bildirilmiştir.1,16 Bizim çalışmamızda 1030 dijital panoramik radyografik görüntü değerlendirildi ve literatürle benzer değerlerde, görüntülerin \% 1.2'sinde $(n=13)$ birden fazla kök ve \%10.2'sinde $(n=106)$ birden fazla kanal morfolojisine sahip olan mandibular premolar diş tespit edildi.

Ülkemizde Ok ve arkadaşlarının çalışmasında ise çoğu mandibular birinci ve ikinci premolar diş tek kanallı olarak bulunmuştur. ${ }^{14}$ Sonat ve arkadaşlarının mandibular birinci ve ikinci premolar dişleri değerlendirdikleri çalışmalarında ise 160 dişin \% 79.37'sinde tek kanal yapısı, \% 20.63'ünde ise birden fazla kanal yapısı bulunmuştur. Bu çalışmada, çalışmamızla benzer şekilde üç kanallı mandibular premolar diş görülmemiştir. ${ }^{12}$ Çalışmamızın sonuçları literatürde farklı ırklarda yapılan çalışmalarla benzer olup mandibular birinci ve ikinci premolar dişler sıklıkla tek köklü ve tek kanallı olarak tespit edilmiştir.

Sert ve ark. çalışmalarında Türk toplumunda kadın ve erkek cinsiyet arasında kanal ve kök morfolojileri açısından farklılık olduğunu belirtmişlerdir ve çalışmalarında kadınlarda mandibular birinci premolar dişlerde \% 44, ikinci premolar dişlerde \% 15 oranında birden çok kanal tespit etmişlerdir. ${ }^{17}$ Aynı grubun erkek hastaları değerlendirdikleri çalışmalarında ise mandibular birinci premolar dişlerin \% 35, ikinci premolar dişlerin ise \% 43 oranında birden fazla kanal yapısına sahip oldukları gösterilmiştir. ${ }^{18} \mathrm{Bu}$ çalışmalarda alt ikinci premolar dişlerin hiçbirinde üç kanal görülmemiştir. ${ }^{17,18}$ Bizim çalışmamızda da 3 kanallı mandibular premolar dişe rastlanmamıştır ancak bu çalışmalardan farklı olarak cinsiyetler arası fark gözlenmemiştir. Sert ve Bayırlı çalışmalarında değerlendirilen dişlerin kök ve kanal yapısının çoğu Vertucci sınıflandırmasına göre yapılırken, bu yönteme uymayan ek 14 kök ve kanal morfolojisi belirlemişlerdir. ${ }^{10} \mathrm{Bu}$ çalışmada mandibular birinci ve ikinci premolar dişlerin kök ve kanal sayıları açısından çalışmamızla benzer şekilde cinsiyetler arası farklılık bulunmamıştır. Ayrıca Vertucci sınıflandırması hariç ek kök ve kanal morfolojisine sahip mandibular premolar diş görülmemiştir.

Kök ve kanal anatomisinin belirlenmesiyle ilgili çalışmalarda sıklıkla geleneksel radyografik yöntemler kullanılmış olup, histolojik kesitlerin mikroskop altında değerlendirilmesi, mikro bilgisayarlı tomografi, konik ışınlı bilgisayarlı tomografi, bilgisayarlı tomografi gibi görüntüleme yöntemleri de kullanılmıştır. ${ }^{13,19,20} \mathrm{Bu}$ çalışmanın temel kısıtlılığı çalışmanın panoramik radyografi yöntemi ile yapılmış olmasıdır. Panoramik radyografiler iki boyutlu görüntü vermeleri sebebiyle süperpoze görüntülere neden olarak bazı durumlarda kök ve kanal sayısını tam olarak belirlemekte yetersiz kalabilirler. $^{21}$

\section{SONUÇ}

Endodontik tedavi esnasında veya bir tedavi başarısız olduğunda, dişlerin kök ve kanal yapılarında muhtemel anatomik varyasyonlar olabileceği akılda tutulmalıdır. Klinisyenlerin tedavi öncesi kök kanal anatomisi ve varyasyonlarının iyi belirlenmesi tedavi başarısını arttırıp istenmeyen komplikasyonların önüne geçebilir. $\mathrm{Bu}$ çalışma mandibular premolar dişlerin \% 98,8 oranında tek kök ve \% 89,8 oranında tek kanal yapısına sahip olduğunu göstermiştir. Bu verilerin endodonti alanında çalışan klinisyenler için tedavi planlaması ve tedavinin prognozunda yol gösterici olabileceği düşünülmektedir. 


\section{KAYNAKLAR}

1. Alkaabi W, AIShwaimi E, Farooq I, Goodis HE, Chogle SM. A Micro-computed tomography study of the root canal morphology of mandibular first premolars in an Emirati population. Med Princ Pract 2017;26.2:118-24.

2. Vertucci F.J. Root canal morphology and its relationship to endodontic procedures. Endod Topics 2005;10:3-29.

3. Ahmad IA, Alenezi MA. Root and root canal morphology of maxillary first premolars: A literature review and clinical considerations. J Endod 2016;42.6:861-72.

4. Er K, Akpınar KE. Anatomik düzensizliklere sahip dişlerde kök kanal tedavisi (3 Olgu Nedeniyle). Cumhuriyet Üniversitesi Diş Hekimliği Fakültesi Dergisi 2002; 5.1:2630.

5. Weine F.S, Healey H.J, Gerstein H, Evanson L. Canal configuration in the mesiobuccal root of the maxillary first molar and its endodontic significance. Oral Surg Oral Med Oral Pathol 1969;28.3:419-25.

6. Vertucci F.J. Root canal anatomy of the human permanent teeth. Oral Surg Oral Med Oral Pathol 1984;58.5:589-99.

7. Sert S, Aslanalp V, Tanalp J. Investigation of the root canal configurations of mandibular permanent teeth in theTurkish population. Int Endod J 2004;37:494-9.

8. Uzun I, Güler B, Özyürek T, Başoğlu F. Evaluation of the root canal diamete rirregularities of mandibular premolars. Journal of Dental Faculty of Atatürk University 2015;25.1:40-46.

9. Cleghorn B.M, Christie WH, Dong CC. The root and root canal morphology of the human mandibular second premolar: a literatüre review. J Endod 2007;33.99:1031-7.

10.Sert S, Bayirli GS. Evaluation of the root canal configurations of the mandibular and maxillary permanent teeth by gender in theTurkish population. $J$ Endod 2004;30.6:391-8.

11.Cleghorn B.M, Christie W.H, Dong CC. The root and root canal morphology of the human mandibular first premolar: a literatüre review. J Endod 2007; 33.5:509-16.

12.Sonat B, Gökay S. Alt küçük azı dişlerinde kanal sisteminin şeffaflaştırma yöntemi ile incelenmesi. Atatürk Üniversitesi Diş Hekimliği Fakültesi Dergisi 1992;19:221-226.

13.Zhang D, Chen J, Lan G, Li M, An J, Wen X, Deng M. The root canal morphology in mandibular first premolars: a comparative evaluation of cone-beam computed tomography and micro-computed tomography. Clinical oral investigations, 2017;21.4:1007-12.

14.Ok E, Altunsoy M, Nur BG, Aglarci OS, Çolak M, Güngör E. A cone-beam computed tomography study of root canal morphology of maxillary and mandibular premolars in a Turkish population. Acta Odontol. Scand. 2014;72.8:701-6.

15. Hoen MM, Pink FE. Contemporary endodontic retreatments: an analysis based on clinical treatment findings. J Endod 2002;28.12:834-6.

16. Nallapati S. Three canal mandibular first and second premolars: a treatment approach. J Endod 2005;31 .6:4746.

17.Sert S, Şahinkesen G, Tunca Y.M, Aslanalp V, Altınova M. Türk toplumunda kadın alt ve üst çene sürekli diş kanal şekillerinin şeffaflaştırma yöntemi ile belirlenmesi. Gülhane Tıp Dergisi 2004;46:93-101.
18. Sert S, Şahinkesen G, Tunca YM, Aslanalp V, Altınova M. Türk toplumunda erkek alt ve üst çene sürekli diş kanal şekillerinin şeffaflaştırma yöntemi ile belirlenmesi. Gülhane Tıp Dergisi 2004;46:93-101.

19.Awawdeh L, Abu Fadaleh M, Al-Qudah A. Mandibular first premolar apical morphology: A stereomicroscopic study. Australian Endodontic Journal, 2019;45.2:233-240.

20.Sun CW, Liu Y, Yang YM, Liao Q. Micro-CT study of root canal morphology of mandibular first premolars with multi-canals. Shanghai kou qiang yi $x u e=$ Shanghai journal of stomatology, 2018;27.1:6.

21.Pharoah MJ, White SC. Oral Radiology Principles and Interpretation. 7th Edition. St. Louis, Mosby, 2013.

Yazışma Adresi:

Ayşe TAŞ

Akdeniz Üniversitesi

Diş Hekimliği Fakültesi

Ağız Diş ve Çene Radyolojisi AD.

Antalya, Türkiye

Tel : +905444347459

E Posta: dtaysetass@gmail.com 